\title{
Evolution Sustainable Green Inner-wall with Flexible Floor Plan
}

\author{
N.M. Tawil ${ }^{1}$, H. A. Hussaini ${ }^{2}$, H. Basri ${ }^{3}$, A. I. Che Ani ${ }^{4}$, M.A.O Mydin ${ }^{5}$ \\ ${ }^{1,2,3,4}$ Faculty of Engineering and Built Environment, Universiti Kebangsaan Malaysia 43600 UKM \\ Bangi, Selangor Malaysia \\ ${ }^{5}$ School of Housing, Building and Planning, Universiti Sains Malaysia, 11800, Penang, Malaysia
}

\begin{abstract}
The trend of renovate residential houses especially the interior of the house has become a common phenomenon for homeowners nowadays in Malaysia. This scenario is quiet concern because sometimes no modifications to comply with the law and the guidelines set by the government housing. Modifications with not done properly can cause injury and harm to families and the people around. To reduce this problem, the concept of sustainable inner walls with flexible floor plan should be incorporated in every house in Malaysia. This is because the wall is the basic structure of a building and usually serves as the border, supporting structures and dividing the space with another space. Wall also causes an increase of the price of a house. This is due to the increase in raw material costs and labor costs, land subsidence have to bear by the developer. The increasing in house prices is causing among Malaysians, especially young executives cannot afford to buy their first home. To reduce the price of the home, reduction in construction interior wall in wet construction should be done and replaced with the sustainable inner wall. This sustainable inner wall also can save the space and the owner simplify can added or reduced the room according their need without spending too much money for renovation in the future.
\end{abstract}

\section{Introduction}

Renovation or remodeling is the process of improving a building either commercial or residential. Additionally, renovation can refer to making something new or changing the building in better condition. Housing forms one of the basic needs of human. Maslow's Theory Hierarchy of Needs sees that housing forms the foremost important needs [1]. Omar, Endut, \& Saruwono [2] has mention, modification of the home has become a 'culture' in Malaysian housing development. It is an act of altering an environment, allowing transformation of house into 'home'. As time goes by, people develop and wanting to improve the state and quality of their house so that they can live their lives towards better meaning parallel to their up growth. In Malaysia, we could see lots of houses being renovated or extended by owners after the houses get dwelled in especially of those terrace housing [3]. The physical adaptation and adjustment made by the occupants to fit their utilitarian needs could result in the extensive modification of the housing facilities and the relocation of spatial distribution [4]. In Malaysia, the trend of renovation is not a new phenomenon because house buyers usually like to renovate their house especially the new house. This scenario is a big concern because all of the renovations that were done without adhering to its legal requirement might harm the occupants and 
their surrounding in the near future. The extension of homeland that articulating the sense of belongingness, expresses through modification of kitchen with additional function as social meeting as well as source of self identity. Traditions and rituals had actually made the place unique and valuable as it differs from other places.

The sudden increasing price house in Malaysia lately had been effect most people and also one of the reason why many owner of the house renovate their house because they cannot afford to buy a better house for their family. The renovation is an alternative to solve the problem. Double-storey terrace house is not a type of house that is cheap [5] This type of house is categorized in a high-cost level. In Selangor, take Bandar Baru Bangi for instance; one unit of double-storey house (40 x 65) square feet could reach RM 400, 000 (Ringgit Malaysia). The problem is that this house is bought at such an expensive price but still needs major renovations. Also, the reason of house renovation in Malaysia based on behavior, unsatisfied with their house and as a hobby. For example, the renovations have been done in particular area such as a walk-in wardrobe, kitchen bedroom and living area [2]. It is common knowledge that kitchen is one of the favorite renovated spaces in local housing and also bedrooms are another feature which is commonly modified. Apart from that, they also need to increase the privacy. So generally almost all of things need to be expanded as the family grows [5].

\section{Flexible Floor Plan}

The concept of flexible floor plan it very suitable and conveniences for sustainable green inner wall. Because the concept flexible floor plan has provided basic needed such as bedroom, living room, kitchen and also toilet. One of the strategies of flexible floor plan concept is to offer the landed property focusing on terrace house with lower house price for middle income group buyer because the construction cost will be reduce by reducing the inner wall [6].

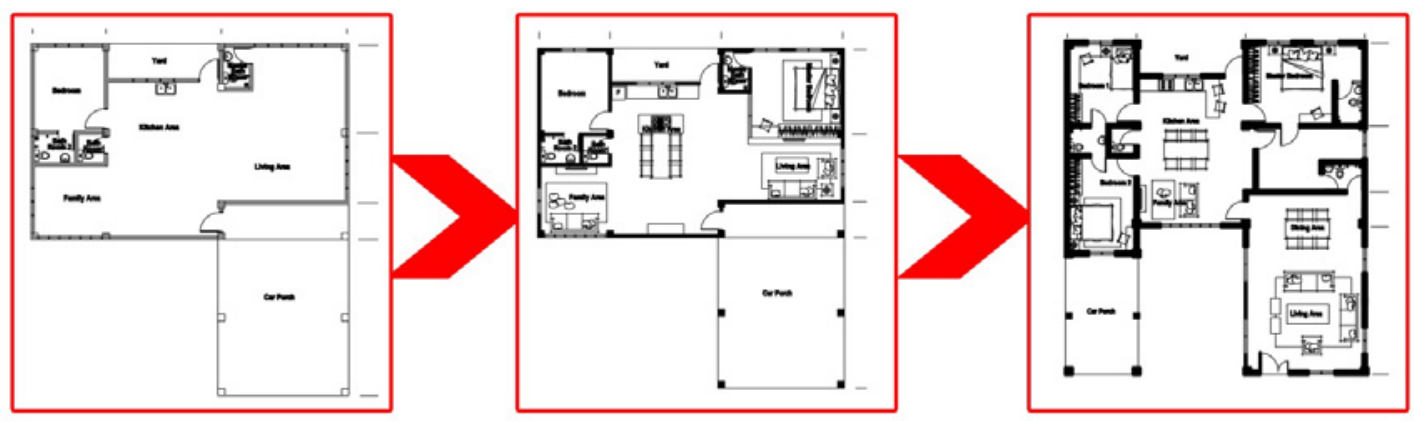

Figure 1: Evolution of house renovation using flexible floor plan with sustainable inner wall.

Based on Figure 1, flexible floor plan has only basic unit like a bedroom, toilet and a big space of living and kitchen area. From time being, owner can modified or renovate their house according their need or interest without spending a lot of money for renovation. The price that those developer put on should be consistently rational to the condition of the house as in design, function, aesthetic and other aspects of the house but this is not the case happening in Malaysia [3]. The evolution from above, the houses only have a basic needed but the owner can renovate or modified their house from one bedroom being a two bedroom or more. Simply, people renovate to suit their personal needs and certain feature or fashion is favored by house owners [7]. From the figure, they just use sustainable green inner wall as a bedroom wall or barrier. So, the cost for renovation can be diminished and also the sustainable green inner wall, it is not only wall but has another function like furniture wall, wardrobe, wall selves, moveable wall and etc. There are a lot of innovative material nowadays in the market produce from waste and recycle material that not only can reduce the environmental impact but also may lower the cost and most important result in a healthier and more comfortable living environment [8]. The result in housing designs that is said to be devoid of basic design principles and 
often, does not match the needs of the ordinary population. In addition, houses are built fast and lacking in creative design efforts [9].

\section{Sustainable Green Inner Wall}

Sustainable products are to provide environmental, social and economic benefits while protecting public health, environment and economic over their whole life cycle, from the extraction of raw until the final disposal. For innovative material nowadays, sustainable green inner wall one of the concepts to reduce the price of renovation and house. Direct involvement of the user in the assembling process of his/her own products or even entire house is a reality among low-income populations in developing countries [10]. Nevertheless, there are a limited number of products that have actually been designed from a do-it-yourself (DIY) perspective, which results in several problems, such as poor user safety while the product is being assembled or inadequate results from an improvised assembling. Using sustainable green inner the space of the room can be save with another purpose. Jamel \& Utaberta, [5] has been stated that the obvious reason why these people did the renovations is that they needed a larger space or area. Plus, there are few people who rearranged or repositioned the guest room to the back of the house to get a larger and flexible kitchen and dining area [11]. In brick and cast-in-place buildings they take $35 \%$ and $6 \%$ of all apartments in multifamily buildings, respectively. The types of buildings are not numerous. They include about seven varieties of largepanel houses, six types of brick and four types of cast-in-place buildings. Omar et al., [2] said the people are getting more alert and attentive about design aspects and they wanted a better house to live their lives.

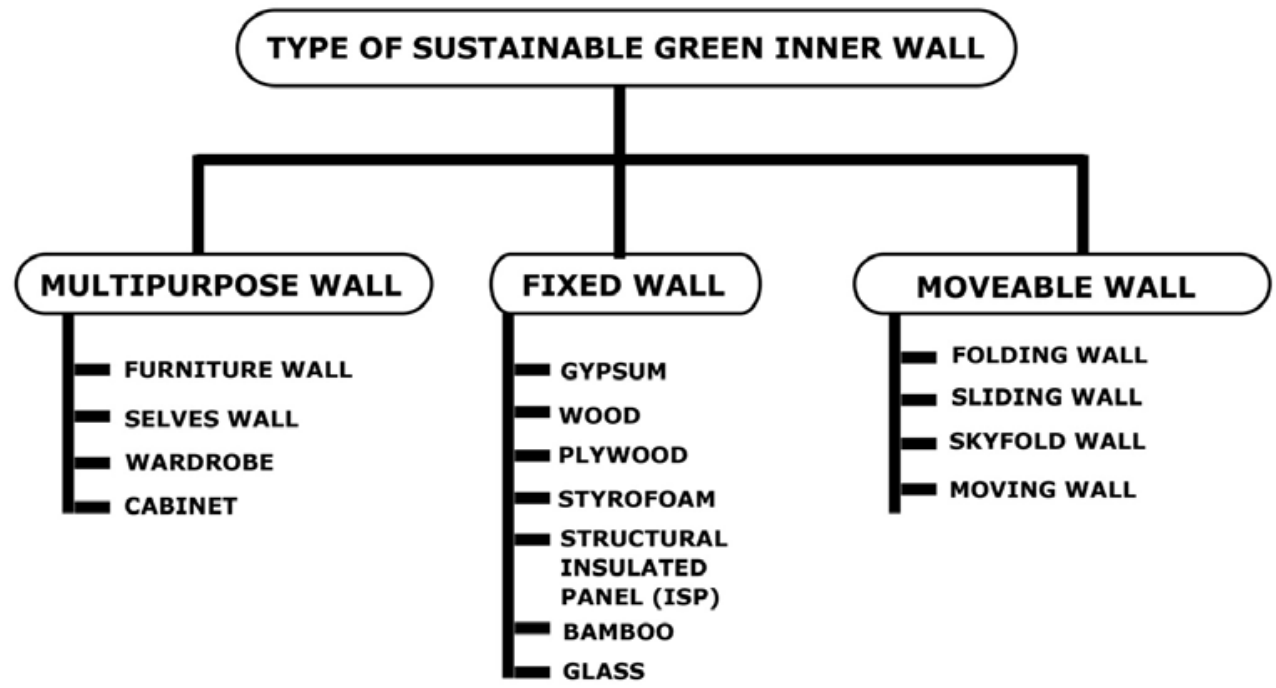

Figure 2: The type of sustainable green inner wall

\section{Multipurpose Wall}

Multipurpose wall also can describe as a furniture wall, selves wall, wardrobe and etc. It also can be a replace a wall and saving the space. Multipurpose wall is the way to go for those with small space or who like to have everything in one place (Home designing). 


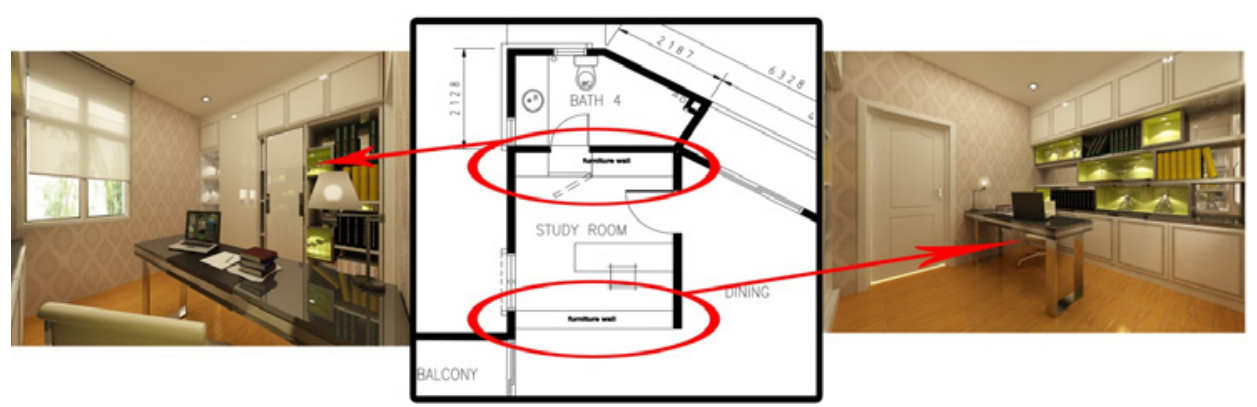

Figure 3: Furniture wall used as a partition or wall to divide with another room or area.

From the Figure 3 we can describe that multipurpose wall can be a wall as a divider and it saving a lot of space for a small room. In this picture we could see using the multipurpose wall their can also create another connection or door to go another place or area without made another wall or door. Furthermore, nowadays a lot of people have a tendency to use open wardrobe as wardrobe in their room, so it saving a lot of space and saving money either then use a wardrobe. Also, using multipurpose wall, they can made built in wardrobe or cabinet as storage. Omar et al., [2] mention when asked on the lack of storage space, all of the homeowners did not comment negatively but informed that they are willing to give up a portion of bedroom space for storage purposes. For time being, they also can change the room into another purpose and function. Also, they can remove the multipurpose wall to make a room a big space without using a lot of money or renovated the whole house or area. While fixing the optimal renovation prices from the aspect of market value increase, the main indicator, limiting the size of investments into building renovation, is the difference between market values after and before renovation [12]. Recently, more attention is paid to sustainable, complex renovation satisfying integration of social, technical, economic, ecological needs of various stakeholder groups [13]. If a scheme of terrace house can provide a design with basic facilities and flexi floor plan, the price of the selling price can be lower thus can be beneficial to middle income group [8].

\section{Fixed Wall}

Gypsum, wood, plywood, Styrofoam, structural insulated panel (SIP), bamboo, composite material and glass is a material for making fixed wall. Using this material, the wall can be made and safely can be removed without using a big construction renovation because they have their own strength. Malmgren, et. al [14] has divide the product in four different views the complexity of the product can be reduced and each view represent the interest of customer, engineering, production and assembly respectively. Wilson [15] present invention relates to a removable wall panel, and particularly to a decorative panel which may be easily and conveniently installed.

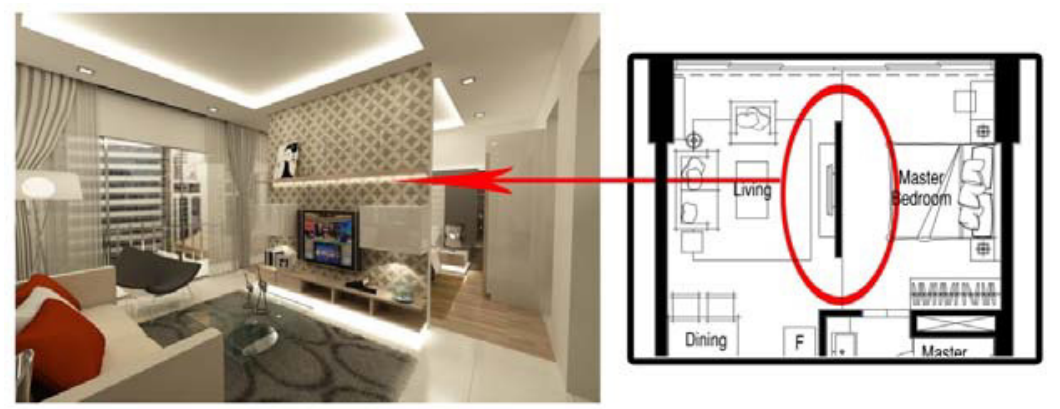

Figure 4: The fixed wall made by gypsum as a divider between living area and bedroom 
By example from figure above, gypsum can be a divider between living area and bedroom because gypsum board are easy to install for several reasons and using dry construction. Preventing the transfer of unwanted sound to adjoining areas is a key consideration when designing a building, specifically when taking into account the intended activities of the occupants in the various parts of the building (Gypsum Association). Gypsum wall board is the most common interior finish used in Canada and the United States. There are several types of gypsum board manufactured for specific purposes.

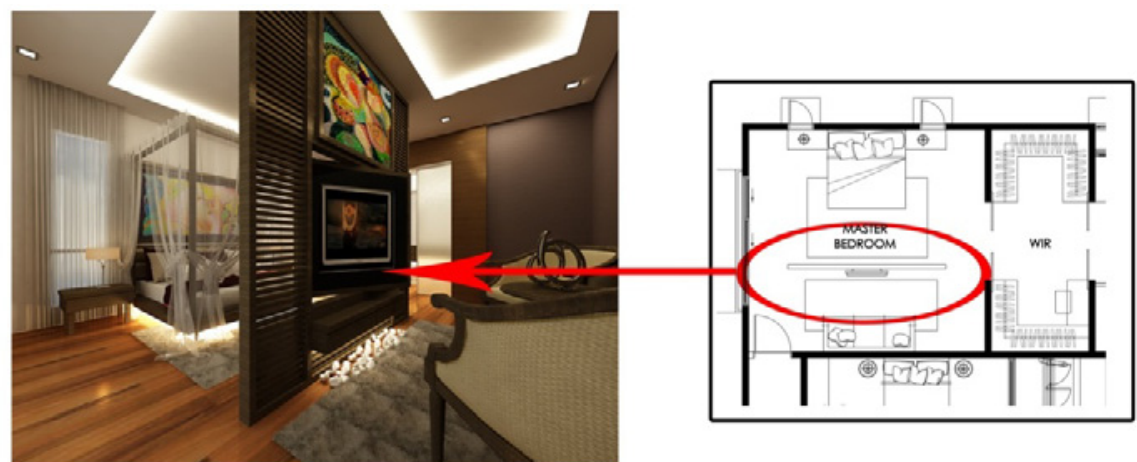

Figure 5: Wood can be a fixed wall and a divider, also as a cabinet for television.

They have many type of wood for wall such as timber, hard word, softwood, lumber and every type of wood has a unique character and sources. Furthermore, glass is quite popular as a partition interior decoration and architecture nowadays because has long been used for its transparency and designed to meet specific requirements. This concept able to help middle income groups to has lower house price and give opportunities for individuals to design and own their dream spaces in the house using Do It Yourself (D.I.Y) [6]

\section{Movable wall}
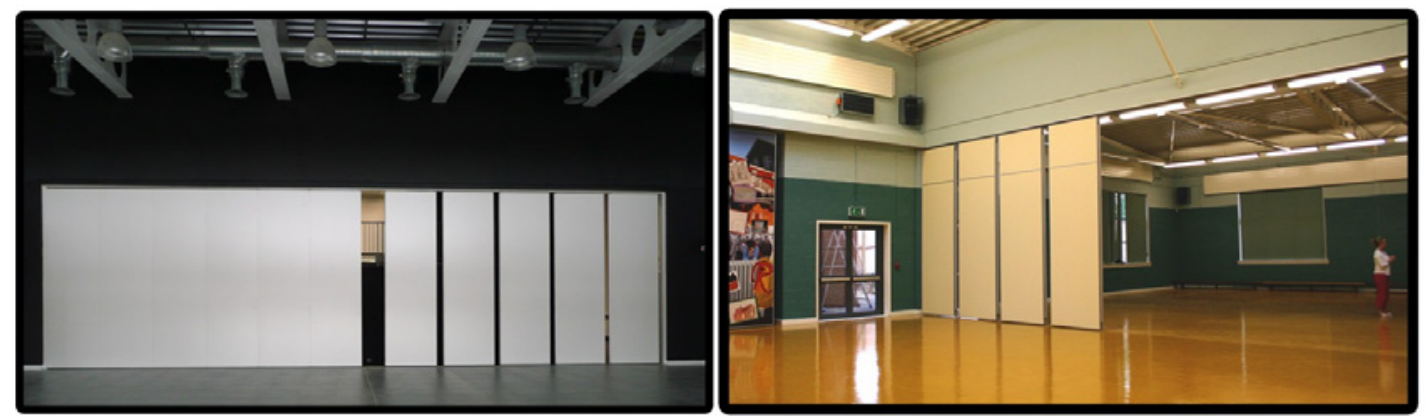

Figure 6: Moveable wall are easy for instalment and just do it by the owner itself

Movable wall is making it possible to divide one room into several different ones and can separate one room into various small rooms. With movable walls it can divide a large room into a smaller one and turn it back into a large room again anytime they want. Movable wall can be a rolling, mobile, sliding or folding room divider which provide temporary walls in place of traditional non mobile products such as operable walls, accordion partitions, cubicles, pipe and drape, and shoji screens. They are sometimes folded and are on wheels enabling mobility and ease of storage. Moveable walls have manufactured in a highly modern facility using innovative hi-tech materials to achieve a very high quality product. The lightweight design makes even large moving wall panels easy to move and reduces structural support requirements [16]. Folding wall which can either be hung 
from a ceiling track or supported by a low profile surface mounted floor track. The movable wall has two full panel end members which provide support, rigidity, privacy and noise reduction. It can divide space quickly where non-mobile permanent room dividers may be unavailable or impracticable. They may also be used as a convenient sight divider to conceal door openings to restrooms, kitchens and other backroom areas. Santos et. al. [10] conclude the DIY approach presents a competitive solution in terms of cost when compared to second-hand furniture and give opportunities for developing DIY solutions for low-income housing.

\section{Conclusion}

Issue housing price and illegal renovation can be solving if we are willing to accept the new method and design. Using sustainable green inner wall with flexible floor plan, the house can be more sustain and economic to use. Also, it can reduce the price of the house and give a lot of benefit for the developer, government and house buyers. The concept of implementing a sustainable green inner-wall with a flexible floor plan helps these people in a way that they can afford to buy their first home and the design evolves according to their needs and family growth. Furthermore, sustainable green inner wall also can educated people about Do-It-Yourself (DIY) concept to help owner redesign and adding another space for their room by himself without carpenter. This method also can educate the citizen of Malaysia especially, to being creative, economic, and being brave to try a new method.

\section{References}

1. Dr Wan Nor Azriyati Wan Abd Aziz, A. P. . D. N. R. H., \& Singaravello, D. K. a/1. (n.d.). A Study On Affordable Housing Within The Middle Income Households In The Major Cities And Towns In Malaysiain in, The study concluded that more government intervention is warranted to address this affordability issue in relation to the types of houses pref, 1-20.

2. Omar, E. O., Endut, E., \& Saruwono, M. (2012). Not Your Perfect Home? How Malaysian Homeowners Make It Works. Procedia - Social and Behavioral Sciences, 42: 350-361.

3. Nangkula Utabertaab, M. A. J. (2011). Renovations and Extensions of Modern Terrace House in Malaysia: A Case Study of Changes and Modification of House in Klang Valey, Malaysia.

4. Saji, N. B. (2012). A Review of Malaysian Terraced House Design and the Tendency of Changing. Journal of Sustainable Development, 5(5), 140-149.

5. Jamel, M. A., \& Utaberta, N. (2011). House Renovations and Extensions in Malaysia: An Investigation of Mechanical Changes and Modification of House in Klang Valey, Malaysia. Advanced Materials Research, 291-294

6. Tawil, N. M., Musa, A. R., Goh, N. A., Beh, C. K., Basri, H., \& Zaharim, A. (2012). Empowering Energy Economics In Housing Renovation With Portable Green Inner Wall For Self Build House 2 Self Build Remodelled House One of the major benefits of building your own 3 Portable Green Inner Walls, 480-483.

7. Zavei, S. J. A. P., \& Jusan, M. M. (2012). Exploring Housing Attributes Selection based on Maslow's Hierarchy of Needs. Procedia - Social and Behavioral Sciences, 42(July 2010), 311319.

8. Tawil, N. M., Musa, A. R., Abdullah, N. A. G., Ani, A. I. C. H. E., \& Basri, H. (2012). An Investigation Of Portable Green Inner Wall For Self Build Remodelled House 3 The Importance of Self-Build Remodel House 4 Criteria for Self-Build Remodel House Construction Method and, 240-244.

9. Saruwono, M., Rashdi, A. M., \& Omar, E. O. (2012). To House-owners, Style Does Matter. Procedia - Social and Behavioral Sciences, 36(June 2011)

10. Santos, A. Dos, Rocha, C. G., \& Lepre, P. (2010). Barriers and Opportunities in Developing “ Do-it-yourself" Products for Low-income Housing, 15 (1), 29-43. 
11. Edmundas Kazimieras Zavadskas L, A. Ras K. 2 And S. R. 2. (2004). Evaluation Of Investments Into Housing Renovation, (October 2013), 37-41.

12. Taylor, P., Zavadskas, E. K., \& Raslanas, S. (N.D.). International Journal Of Strategic Property Management, (October 2013), 37-41.

13. Kaklauskas, A., Naimaviciene, J., Tupenaite, L., Kanapeckiene, L. (2007). Knowledge Base Model For Sustainable Housing Renovation, Vol 1(In The 9th International Conference "Modern Building Materials, Structures And Techniques), Pg 3.

14. Malmgren, L., Jensen, P., \& Olofsson, T. (2010). Product Modeling Of Configurable Building Systems - A Case Study, 15: 354-368.

15. Wilson, W. J. (1988). Removable Wall Panel. United States Patent.

16. Style, moveable partition specialists, http://style-partitions.co.uk update 2013 